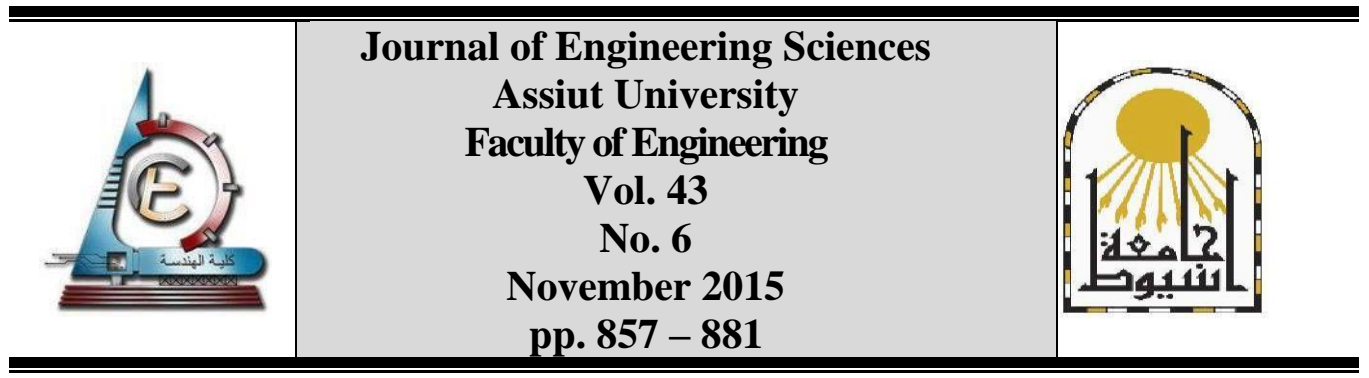

\title{
SYNERGY OF SIMULATED ANNEALING AND PARTICLE SWARM ALGORITHMS FOR OPTIMIZING STATCOM DAMPING CONTROLLER
}

\author{
Ahmed A. A. Hafez \\ Electrical Engineering Department, Faculty of Engineering, Assiut University, Assiut, Egypt
}

(Received 17 August 2015; Accepted 8 October 2015)

\begin{abstract}
Synergy of Simulated Annealing (SA) and Particle Swarm Optimization (PSO) for optimal design of Static Synchronous Compensator (STATCOM) controller is advised in this article. The advised SA-PSO algorithm remedies the premature convergence and parameter dependency of PSO via SA probabilistic jumping property, metropolis process. The STATCOM controller design is formulated as nonlinear constrained optimization problem. The objective function considers the key operating states, while satisfying a predesigned stability margin and achieving performance objectives. The advised SA-PSO efficiently damps the power system oscillations following severe disturbance/fault conditions, while fulfilling the STATCOM basic function in regulating voltage profiles and confining with the operational limits. The dynamic performance of the Single Machine Infinite Bus (SMIB) and Multi Machine Power (MMP) systems equipped with STATCOM tuned via PSO, SA and SA-PSO is investigated under different operating conditions. The functionality of STATCOM stabilizing controller to restore SMIB system stability under different disturbances and loading conditions is verified. Furthermore, STATCOM damping controller capability of maintaining stability under fault scenarios is corroborated for MMP system. The comprehensive simulation results from SMIB and MMP systems demonstrate robustness, effectiveness, and visibility of the advised SA-PSO in tuning STATCOM compared with PSO and SA.
\end{abstract}

Keywords: Static Synchronous Compensator, Particle Swarm Optimization, Simulated Annealing, Hybrid, Single-Machine Infinite Bus System, Multi-Machine Power System, Disturbances, Faults.

\section{Introduction}

Recently, Flexible AC Transmission Systems (FACTS) configurations are widely dispersed in power utilizes to replace conventional Static VAR Compensator (SVC) as Thyristor Switched Reactors/Capacitors (TSR/TSC). The emerging topologies of FACTS in general enjoy reduced volumetric dimension, adequate performance and fast response. They could instantaneously regulate the flow of active and reactive powers, maintain voltage profile within allowable limits and increase power transfer capabilities of transmission circuits [1-6].

STATCOM is one of the promising FACTS [2, 3, 7]. It has the ability of continuous regulation of reactive power and hence system voltage profiles. This is attributed to its 
operating principle in utilizing solid-state devices rather than fixed shunt capacitors/reactors [2, 3, 7-9].

STATCOM in general is an active device, which control magnitude and phase of the compensated voltage almost instantaneously. Therefore, it independently regulates the reactive power flow. STATCOM acts as source/sink for the reactive power, which increases the transferred active power and regulates system voltages. Moreover STATCOM is basically parallel connected, thus it enjoys reduced volumetric dimension and rating.

STATCOM is investigated for improving power quality and damping power system oscillations following the disturbances[7-11]. This is accomplished via imposing auxiliary controller on the STATCOM main controller. Different control arrangements are reported in the literature for implementing this auxiliary controller; however, the simple lead-lag controller is considered the most promising option $[4,7,9,10]$. This may be attributed to the advantages of this controller as: -

- Simple structure,

- Convenient adjustment and,

- Easily online tuning.

The parameters of that controller are set principally by eigenvalue techniques. However, eigenvalue scheme usually considers the critical nodes only. This results in a significant degradation in damping of non-critical modes. Thus, the controller design should consider two main criteria [4, 7, 9]:

- Providing robust damping for all operating points and loading levels including critical ones,

- Operating within the allowed boundaries of STATCOM.

Recently, the tuning of STATCOM damping controller is investigated as a constrained optimization problem. Stochastic global searching algorithms [12], which are based on stochastic search with some heuristic behaviors, are employed for finding the optimal parameters. These algorithms are in the form of probabilistic heuristics, with global search properties [13-24]. They have the ability to reach an optimum solution without previous knowledge of the problem. These approaches include PSO [13-17], genetic algorithm [18, 19], bacterial foraging [20], differential evolution [21, 23], multi-objective evolutionary algorithm[22] and simulated annealing algorithm [24]. Generally, these techniques move from one point in the decision hyperspace to another through some deterministic rule [1224]. Some of these techniques are usually stuck at a local optimal.

PSO search approach simulates the behavior of individuals of the species whom work for the benefit of the entire group. It is based on swarm concept; the particles in the swarm adjust their performance i.e. flying speed/ direction according to the experience of their own and the other in the swarm, through robust communication. PSO a random search algorithm with a parallel structure. It enjoys the advantages of a simple structure and fast convergence. However, the principal adversity of the PSO is premature convergence that results when a particle and the group best solutions are trapped into local minimums during the search process[13-15, 20, 25-29].Moreover, PSO suffers from parameter dependency.

$\mathrm{SA}$ is a combinatorial optimization technique based on random evaluation of the objective function. Physically, SA simulates the actual cooling process of molten metals through annealing. SA enjoys the capability of finding global optimum with a high 
Ahmed A. A. Hafez, Synergy of simulated annealing and particle swarm algorithms for .........

probability even for ill-conditioned functions with numerous local optima. This is attributed to the salient characteristic of SA that is its probabilistic jumping criterion, called the metropolis process. Moreover, the metropolis process is easily controlled by adjusting the temperature,. It has been theoretically proven that the SA technique converges asymptotically to the global optimum solution with probability one provided that certain conditions are satisfied. However, SA may require large number of function evaluations, which increase computation requirements [30-35].

Therefore, this paper advise a novel SA-PSO approach that takes the advantages of the intrinsic characteristics of SA algorithm in converging to optimal solution across the entire domain, and of PSO in fast calculation. The proposed SA-PSO can generate high-quality solutions with less computation requirements and offers more stable convergence characteristics.

In this article, the novel hybrid SA-PSO is used for optimizing the performance of SMIB and MMP systems equipped STATCOM. The selection of optimal parameters for STATCOM controller is treated as constrained optimization problems. The objective functions minimize the integral of absolute errors of key operating states, while providing adequate stability margin. The feasibility and the effectiveness of the advised SA-PSO algorithm were demonstrated by evaluating the performance of SMIB and MMP systems subjected to wide range of disturbances. Comprehensive simulations in Matlab platform for SMIB and MMP systems while STATCOM controller tuned with SA, PSO and advised SAPSO methods are carried out. The results validates the visibility and superiority of SA-PSO compared with SA and PSO either in solution quality and/or computational efficiency.

\section{Single machine infinite bus system}

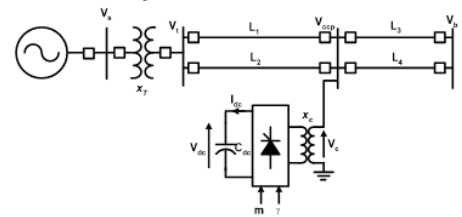

Fig. 1. SMIB power system equipped with STATCOM

Figure 1 shows the system under concern. It is SMIB equipped with STATCOM. SMIB is composed of a synchronous generator connected to infinite bus, $\mathrm{V}_{\mathrm{b}}$, via transmission lines $\mathrm{L}_{1}-\mathrm{L}_{4}$ and step-up transformer. The STATCOM is connected to the Common Coupling Point (CCP) at bus $\mathrm{V}_{\text {ccp }}$ through step-up transformer. The bus $\mathrm{V}_{\text {ccp }}$ is connected to the generator through lines $\mathrm{L}_{1}$ and $\mathrm{L}_{2}$ and to the infinite bus $\mathrm{V}_{\mathrm{b}}$ via lines $\mathrm{L}_{3}$ and $\mathrm{L}_{4}$.

In this research, the $3^{\text {rd }}$ order model is used for depicting the performance of synchronous generator. The $3^{\text {rd }}$ order model is considered to be a good compromise between computation speed and complexity. In this model, the machine performance could be obtained by electromechanical swing equations and the generator internal voltage equation [4, 36, 39],

$$
\begin{gathered}
\dot{\delta}=\omega_{s}(\omega-1) \\
\dot{\omega}=\frac{1}{M}\left(P_{m}-P_{e}-D(\omega-1)\right) \\
\cdot E_{q}^{\prime}=\frac{1}{T_{d o}^{\prime}}\left(E_{f d}-E_{q}\right)
\end{gathered}
$$


where $M$ is the inertia constant; $D$ is the friction coefficient, $T_{d o}^{\prime}$ is transient time constant of d-axis. $\delta$ and $\omega$ are rotor angle and speed respectively. $\omega_{s}, P_{e}$ and $P_{m}$ are base speed, output and input powers respectively. $\mathrm{E}_{\mathrm{q}}^{\prime}$ is $\mathrm{q}$-axis transient voltage. $\mathrm{E}_{\mathrm{q}}$ is $\mathrm{q}$-axis internal voltage and $\mathrm{E}_{\mathrm{fd}}$ is field voltage .

$$
\begin{aligned}
& P_{e}=E_{q}^{\prime} I_{q}+\left(x_{q}-\mathrm{x}_{d}^{\prime}\right) I_{d} I_{q} \\
& E_{q}=E_{q}^{\prime}+\left(x_{d}-\mathrm{x}_{d}^{\prime}\right) I_{d}
\end{aligned}
$$

where $I_{d}$ and $I_{q}$ are $d$ and $q$ axes components of the generator line current $I_{s}$ respectively. Equation (4) relates the generated power to transient voltage, currents and synchronous reactance of the synchronous generator, while (5) relates internal voltage to transient voltage and d-axis reactance.

The generator terminal voltage $\mathrm{V}_{\mathrm{s}}$ is related to transient voltage on q-axis, line current components and generator reactances by,

$$
V_{s}=\left(\left(E_{q}^{\prime}-\mathrm{X}_{d}^{\prime} I_{d}\right)^{2}+\left(x_{q} I_{q}\right)^{2}\right)^{\frac{1}{2}}
$$

Usually in SMIB, IEEE ST1A type excitation is adopted. The transient of the excitation system could be expressed by $[4,16,37]$,

$$
\dot{E_{f d}}=-\frac{1}{T_{A}} E_{f d}+\frac{K_{A}}{T_{A}}\left(V_{r e f s}-V_{s}\right)
$$

where $T_{A}$ and $K_{A}$ are time constant and gain of the excitation system respectively. $V_{\text {refs }}$ is the reference value for the terminal voltage.

The performance of SIMB is depicted by a $4^{\text {th }}$ order model; three differential equations are for the machine (1)-(3), while the fourth, (7), is for the excitation.

STATCOM is generally composed of a Gate Turn-Off based Voltage Source Converter (VSC) that connected to CCP through a boosting transformer with leakage reactance $\mathrm{X}_{\mathrm{c}}$, .A sufficiently large DC capacitor $\mathrm{C}_{\mathrm{DC}}$ is allocated on the $\mathrm{DC}$ side of $\mathrm{VSC}$ to maintain the DC-link voltage $\mathrm{V}_{\mathrm{DC}}$ nearly constant.

STATCOM could be considered as synchronous voltage source, $\mathrm{V}_{\mathrm{c}}$, with variable amplitude $m V_{d c}$ and angle $\gamma$, as given by [9],

$$
V_{c}=m V_{d c}(\cos \gamma+i \sin \gamma)
$$

where $\mathrm{m}$ is the modulation index of the VSC. The angle $\gamma$ is measured with respect to the voltage at CCP, $\mathrm{V}_{\text {ccp }}$. STATCOM complex power, $\mathrm{S}_{\mathrm{c}}$, could be computed from [7-9],

$$
S_{c}=\frac{3 V_{c} V_{c c p}}{x_{c}} \sin (\delta)-i\left(\frac{3 V_{c} V_{c c p}}{x_{c}} \cos (\delta)-\frac{3 V_{c c p}{ }^{2}}{x_{c}}\right)
$$

Ideally, $\gamma=0$, thus the STATCOM reactive power Qc is given by, 


$$
Q_{c}=\frac{3 V_{c c p}}{x_{c}}\left(V_{c}-V_{c c p}\right)
$$

The direction/sign of reactive power flow depends on magnitude of STATCOM voltage, $\mathrm{V}_{\mathrm{c}}$, relative to the voltage of CCP, $\mathrm{V}_{\mathrm{ccp}}$, and hence on the DC-voltage $\mathrm{V}_{\mathrm{dc}}$ and the modulation index $\mathrm{m}$. Usually, angle $\gamma$ is nonzero, which allows active power to be transferred to the DClink of VSC. The $\mathrm{d}$ and q axis components of STATCOM output current, $\mathrm{I}_{\mathrm{st}}$, are given by,

$$
\mathrm{I}_{\mathrm{st}}=\left(\mathrm{I}_{\mathrm{std}}+\mathrm{i} \mathrm{I}_{\mathrm{stq}}\right)
$$

where $I_{\text {std }}$ and $I_{\text {stq }}$ are $d$ and $q$ axis components of STATCOM line current respectively. The dynamics of the STATCOM could be obtained by equating the instantaneous input and output powers of STATCOM, and assuming that the energy storage capacitor $\mathrm{C}_{\mathrm{dc}}$ is lossless. The DC-link voltage of STATCOM $\mathrm{V}_{\mathrm{dc}}$ is assumed constant. Thus, the dynamics of STATCOM is given by,

$$
\dot{V_{d c}}=\frac{m}{C_{d c}}\left(I_{s t d} \cos (\gamma)+I_{s t q} \sin (\gamma)\right)
$$

Referring to Figure 1, the generator and STATCOM current components could be obtained from the parameters of the system under concern as,

$$
\begin{aligned}
I_{d}= & \frac{\left(1+\frac{x_{F}}{x_{c}}\right) E_{q}^{\prime}-\frac{x_{F}}{x_{c}} m V_{D C} \sin (\gamma)-V_{b} \cos (\delta)}{x_{P}+x_{F}+\frac{x_{P}}{x_{F}}+\left(1+\frac{x_{F}}{x_{c}}\right) \mathrm{x}_{d}^{\prime}} \\
I_{q}= & \frac{\frac{x_{F}}{x_{c}} m V_{D C} \cos (\gamma)+V_{b} \sin (\delta)}{x_{P}+x_{F}+\frac{x_{P}}{x_{F}}+\left(1+\frac{x_{F}}{x_{c}}\right) \mathrm{x}_{q}} \\
I_{s t d}= & \frac{E_{q}^{\prime}}{x_{c}}-\frac{\left(\mathrm{x}_{d}^{\prime}+x_{P}\right) I_{q}}{x_{c}}-\frac{m V_{D C} \sin (\gamma)}{x_{c}} \\
I_{s t q}= & -\frac{\left(\mathrm{x}_{d}^{\prime}+x_{P}\right) I_{q}}{x_{c}}+\frac{m V_{D C} \cos (\gamma)}{x_{c}}
\end{aligned}
$$

where $x_{\mathrm{P}}=x_{1} / 2, x_{\mathrm{F}}=x_{\mathrm{T}}+x_{1}, x_{1}$ is the inductance of a transmission line. The lines $\mathrm{L}_{1}-\mathrm{L}_{4}$ are assumed to have the same length and hence the same inductance $x_{1}$.

\section{Small-Signal model of SMIB system}

The above equations are linearized around nominal operating point. In obtaining the linearized model, the time constant of the prime mover is assumed sufficiently long such that $\mathrm{P}_{\mathrm{m}}$ in (2) is considered constant.

$$
\Delta \dot{\delta}=\omega_{s} \Delta \omega
$$




$$
\begin{gathered}
\dot{\Delta \omega}=\frac{1}{M}\left(-\Delta P_{e}-D \Delta \omega\right) \\
\Delta E_{q}^{\prime}=\frac{1}{T_{d o}^{\prime}}\left(\Delta E_{f d}-\Delta E_{q}\right) \\
\Delta \dot{E}_{f d}=-\frac{1}{T_{A}} \Delta E_{f d}+\frac{K_{A}}{T_{A}}\left(\Delta V_{r e f s}-\Delta V_{s}\right)
\end{gathered}
$$

Substituting (9)-(12) into (4), (5) and (9) and linearizing around an operating point,

$$
\begin{aligned}
& \Delta P_{e}=k_{1} \Delta \delta+k_{2} \Delta E_{q}^{\prime}+k_{3} \Delta V_{d c}+k_{p m} \Delta m+k_{p \gamma} \Delta \gamma \\
& \Delta E_{q}=k_{4} \Delta \delta+k_{5} \Delta E_{q}^{\prime}+k_{6} \Delta V_{d c}+k_{e m} \Delta m+k_{e \gamma} \Delta \gamma \\
& \Delta V_{s}=k_{7} \Delta \delta+k_{8} \Delta E_{q}^{\prime}+k_{9} \Delta V_{d c}+k_{v m} \Delta m+k_{v y} \Delta \gamma \\
& \Delta V_{d c}=k_{10} \Delta \delta+k_{11} \Delta E_{q}^{\prime}+k_{12} \Delta V_{d c}+k_{d m} \Delta m+k_{d y} \Delta \gamma
\end{aligned}
$$

The linearization constants $\mathrm{k}_{1}-\mathrm{k}_{12}, \mathrm{k}_{\mathrm{pm}}, \mathrm{k}_{\mathrm{em}}, \mathrm{k}_{\mathrm{vm}}, \mathrm{k}_{\mathrm{dm}}, \mathrm{k}_{\mathrm{py}}, \mathrm{k}_{\mathrm{ey}}, \mathrm{k}_{\mathrm{vy}}$, and $\mathrm{k}_{\mathrm{d} \gamma}$ depend on operating points. Thus, the advised SA-PS technique would consider wide range of loading levels and operating conditions, which simulated all possible operating scenarios for the system under concern. The system-space model of the system under concern is given by,

$$
\dot{X}=A X+B u
$$

where $\mathrm{X}$ is state vector and given by,

$$
X=\left[\begin{array}{lllll}
\Delta \delta & \Delta \omega & \Delta E_{q}^{\prime} & \Delta E_{f d} & \Delta V_{d c}
\end{array}\right]^{T}
$$

The control vector $\mathrm{u}$ is given by,

$$
u=\left[\begin{array}{ll}
\Delta m & \Delta \gamma
\end{array}\right]
$$

The state and input matrices are given by

$$
A=\left[\begin{array}{ccccc}
0 & \omega_{s} & 0 & 0 & 0 \\
-\frac{k_{1}}{M} & -\frac{D}{M} & -\frac{k_{2}}{M} & 0 & -\frac{k_{3}}{M} \\
-\frac{k_{4}}{T_{d o}^{\prime}} & 0 & -\frac{k_{5}}{T_{d o}^{\prime}} & -\frac{1}{T_{d o}^{\prime}} & -\frac{k_{6}}{T_{d o}^{\prime}} \\
-\frac{k_{A} k_{7}}{T_{A}} & 0 & -\frac{k_{A} k_{8}}{T_{A}} & -\frac{1}{T_{A}} & -\frac{k_{A} k_{9}}{T_{A}} \\
k_{10} & 0 & k_{11} & 0 & k_{12}
\end{array}\right]
$$

Eigenvalues obtained from plant matrix A is considered here as measure for system stability. As it reported in $[4,38]$ that a stable system should have all eigenvalues with negative real part. 
Our main objective here is to tune SSSC such that a sufficient margin of stability is realized while limiting the overshoot. This will be achieved through the objective function of SA-PSO.

$$
B=\left[\begin{array}{cc}
0 & 0 \\
-\frac{k_{p m}}{M} & -\frac{k_{p \gamma}}{M} \\
-\frac{k_{e m}}{T_{d o}^{\prime}} & -\frac{k_{e \gamma}}{T_{d o}^{\prime}} \\
-\frac{k_{A} k_{v m}}{T_{A}} & -\frac{k_{A} k_{v \gamma}}{T_{A}} \\
k_{d m} & k_{d \gamma}
\end{array}\right]
$$

The hybrid SA-PS combines the advantages of SA and PS techniques, and avoids their limitations. SA-PSO produces high-quality solutions with less computation burden in terms of storage space and time. SA-PSO avoids trapping into local minimum while reducing number of objective function evaluation. Moreover, SA-PSO is easily realizable, robust and stable [13-16, 24-31, 33-35].

\subsection{PSO technique}

The PSO technique could be summarized in the following four steps as,

- Uniform distribution is used to randomly create a particle swarm.

- Each particle represents a feasible solution to the problem; the particle swarm refers to the best experience of the individual, and the best experience of the group.

- Transition from a point into another in hyperspace is performed logically according to the fitness function.

- The particle swarm gravitate towards the optimum solution after continuous iterations

These generic steps are interpreted mathematically in the following. Population of particles is placed in d-dimensional search space, where their initial positions and speeds are chosen randomly. The velocity of each particle is regulated according to the flying experience of its own and that of other particles in the population as,

$$
v_{i}^{k+1}=w_{i} v_{i}^{k}+c_{1} \text { rand }\left(\text { pbest }_{i}^{k}-s_{i}^{k}\right)+c_{2} \text { rand }\left(\text { gbest }-s_{i}^{k}\right)
$$

where $v_{i}^{k+1}, v_{i}^{k}$ are the updated velocity at $\mathrm{k}+1$ iteration and current velocity at iteration $\mathrm{k}$ of $\mathrm{i}$ particle respectively. pbest $^{\mathrm{k}}{ }_{\mathrm{i}}$ and gbest are the best position for the particle $\mathrm{i}$ at iteration $\mathrm{k}$ and the global best position for the group so far. $s_{i}^{k}$ is the current position of particle i. $w_{\mathrm{i}}$ is the inertia weight of particle $\mathrm{i}$. The positive parameters of PSO $\mathrm{c}_{1}$ and $\mathrm{c}_{2}$ are usually chosen between 0.5 to $2[16,27,28]$. The updated position of a particle $\mathrm{i}, s_{i}^{k+1}$ is related to the current position $s_{i}^{k}$ and the updated velocity $v_{i}^{k+1}$ by $[26,27]$,

$$
S_{i}^{k+1}=S_{i}^{k}+v_{i}^{k+1}
$$


The value of the fitness function is computed for i particle and compared with the current best position pbest ${ }^{\mathrm{k}}$. Also, the pbest ${ }_{\mathrm{i}}^{\mathrm{k}}$ is compared with gbest; this is to improve the flying experience of the particles. The number of the particles with position better than gbest is stored. And gbest is updated accordingly. This process continues until reaching to global best position or the predetermined maximum iteration number.

$w_{\mathrm{i}}$ the inertia weight of particle is given by,

$$
w_{i}=w_{i \max }-\frac{w_{i \max }-w_{i \min }}{T_{i \max }} T_{i}
$$

where $w_{\text {imax }}, w_{\text {imin }}, \mathrm{T}_{\text {imax }}$ and $\mathrm{T}_{\mathrm{i}}$ are maximum weight, minimum weight, maximum iterative time and iterative time respectively. Usually $\mathrm{w}_{\mathrm{i}}$ varies within the range 0.4 to 0.9 $[16,27,28]$. The maximum value of particle velocity is given by,

$$
v_{i}^{k+1}= \begin{cases}v_{i}^{k+1} & v_{i}^{k+1} \mid \mathrm{p} v_{\text {max }} \\ v_{\text {max }} & v_{i}^{k+1} \geq v_{\text {max }} \\ -v_{\text {max }} & v_{i}^{k+1} \leq-v_{\text {max }}\end{cases}
$$

where $v_{\text {max }}$ is maximum allowable velocity of a particle.

\section{2. $S A$}

SA is meta-heuristic optimization technique that employs probabilistic Metropolis process for reaching the optimum solution. Basically, SA simulates the annealing process of the metals. The performance of SA mainly depends on a number of factors; these are [31, 32, 35]: initial temperature, disturbance mechanism, equilibrium condition and cooling method. A brief discussion for these factors is given below, however, more details could be found in $[31,32,35]$.

- Initial temperature

- The initial temperature should be carefully selected to avoid trapping in local minima or prolonging the optimization time.

- Disturbance mechanism

Disturbance mechanism is the controlling factor during the metropolis process. In order to explore the search universe and jump away from local optimum, SA use probability based Metropolis acceptance rule, which sets the probability for accepting poor solutions. This rule is given by,

$$
p=e^{-\Delta E / k T_{i}}
$$

where $\mathrm{p}, \mathrm{k}, \mathrm{T}_{\mathrm{i}}$ are probability, Boltzmann coefficient, and temperature at time $\mathrm{i}$ respectively. $\Delta \mathrm{E}$ is the cost difference between the current and neighboring solutions.

- Equilibrium condition:

A system in equilibrium condition implies that there is no change in energy at constant temperature. The acceptance rate is taken as a measure for the equilibrium. The values of the acceptance rate that are close to 1 refer to wide variation in the energy, which requires continuation of disturbance at this temperature level. Acceptance rates close to zero 
indicate that system reaches equilibrium at this temperature level, and the temperature should be reduced if global optimum is not realized.

- Method of cooling:

Annealing process usually involves cooling at a rate complies with temperature decreases. In SA, the temperature is reduced by a factor that could be constant or variable. The transfer from high to low temperature depends principally on acceptance rate. Usually, temperature is reduced by,

$$
T_{i+1}=\alpha T_{i}
$$

where $\alpha$ is temperature reduction coefficient, $\alpha<1$.

The flowchart for SA used in this work given in the Figure 2: The major steps in SA algorithm applied in this research are described as:

- Step 1: Set the initial temperature, number of iteration, system parameters, loading level. The temperature reduction factor is chosen here as $\alpha=0.5$.

- Step 2: Evaluate the objective function value and initialize the iteration number as $\mathrm{i}=1$.

- Step3: Generate a solution from the neighborhood of the current solution. Compute the difference in the energy between the current solution and that in the neighborhood, $\Delta \mathrm{E}$.

- Step4: Examining $\Delta \mathrm{E}$, if it is positive, the Metropolis acceptance rule (34) is used to decide whether to accept or reject the current point.

- Step 5: Update the iteration number as $\mathrm{i}=\mathrm{i}+1$. If $\mathrm{i}$ is less than $\mathrm{N}$ proceed to step3.

- Step 6: Examining the acceptance rule to decide whether to continue in the disturbance at this temperature level, or reduce the temperature using (35).

- Step 7: If stop criteria is not satisfied, the program is recycled from step 3.

The flow chart that depicts steps 2-7 is given in Figure 2.

\subsection{Modeling of hybrid SA-PSO technique}

In the hybrid SA-PSO, particle swarms are randomly generated. A new position for each particle in the swarm is determined using (31). The new position is tested using Metropolis acceptance rule to determine whether to accept or search for another new position. If new position is not satisfying Metropolis criteria; a different new position is computed using PSO . This is repeated until the metropolis acceptance rule accepts the new position, or the upper limit of disturbances is reached. This process directs the search into pbest and gbest. This implementation of SA-PSO enables the solution to jump out of local optima, and decreases the vibration near the end of locating a solution. These characteristics improve the quality of the solution and increase the rate of convergence. In this way, the algorithm can explore for solutions in more paths, increasing the probability that the global optima is found. In addition, the parallel processing capabilities of PSO reduces calculation time. The flowchart in Figure 3 reveals the proposed SA-PSO. 


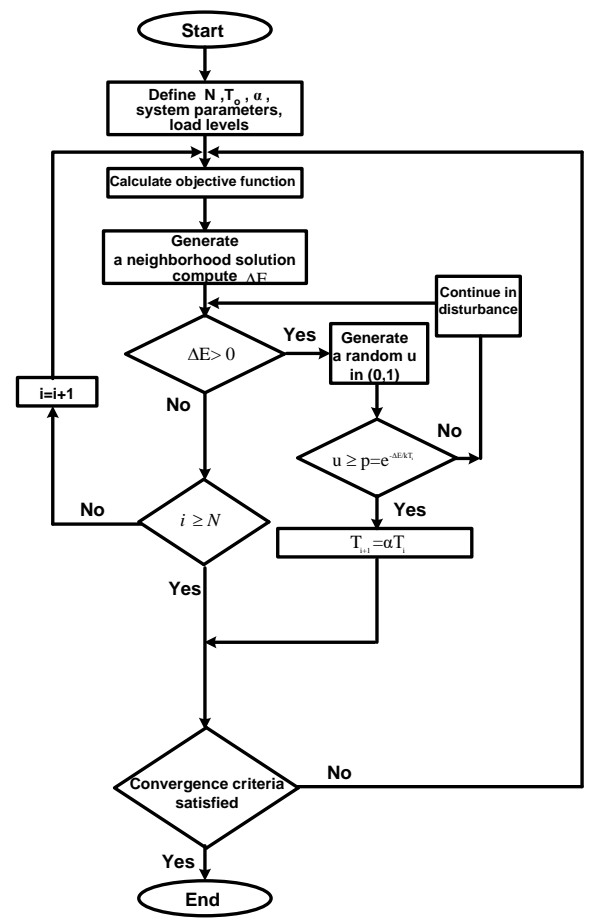

Fig. 2. Flowchart of SA algorithm

The number of iterations N, Figure 2, is taken around 100, which is considered a good compromise between the accuracy and computation time.

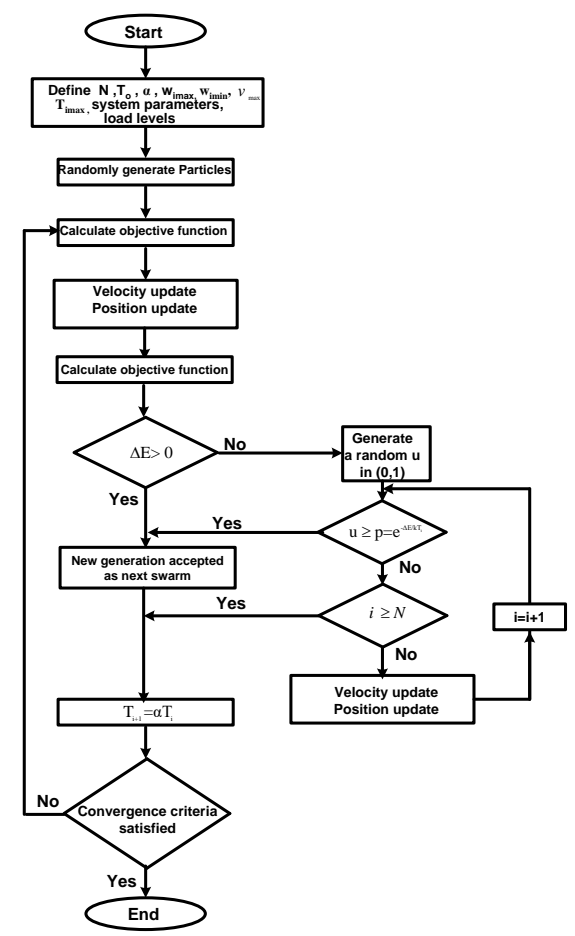

Fig. 3. Flowchart of SA-PSO algorithm 
Ahmed A. A. Hafez, Synergy of simulated annealing and particle swarm algorithms for .........

\section{Tuning of STATCOM in SMIB system}

STATCOM is controlled principally by two decoupled loops as shown in Figure 4. These are modulation index $\mathrm{m}$ and phase angle $\gamma$ loops.

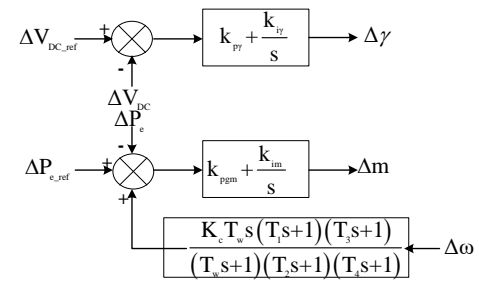

Fig. 4. Modulation index and phase angle loops of STATCOM Controller with the auxiliary controller

where $\mathrm{k}_{\mathrm{pgm}}$ and $\mathrm{k}_{\mathrm{im}}$ are the proportional and integral gains respectively of the modulation index loop. $\mathrm{T}_{\mathrm{w}}$ is the wash-out time constant for AC voltage regulator and additional controller, $\mathrm{K}_{\mathrm{c}}, \mathrm{T}_{1}, \mathrm{~T}_{2}, \mathrm{~T}_{3}, \mathrm{~T}_{4}$ are the parameters of the stabilizing controller. The proportional $\mathrm{k}_{\mathrm{p} \gamma}$ and integral $\mathrm{k}_{\mathrm{i} \gamma}$ gains of the compensator of the DC-link voltage loop.

The DC voltage $\mathrm{V}_{\mathrm{DC}}$ of the STATCOM DC side is regulated by adjusting the phase angle $\gamma$ and hence the active power flow between the STATCOM and point of common coupling. A conventional PI controller is usually used in this loop for fulfilling the control requirement. The wash-out circuit is mainly used to block the response in case of sustained steady-state changes such as load changes. Moreover, the wash-out circuit maybe used for removing switching ripples and undesired harmonics from the feedback measured DC voltage $\mathrm{V}_{\mathrm{DC}}$ signal.

Modulation index $\mathrm{m}$ as mentioned in Section 2 controls the magnitude of STATCOM AC voltage assuming that DC voltage is kept constant, and hence the magnitude and direction of the reactive power. Usually the auxiliary stabilizing task of the STATCOM is achieved by modulating the modulation index $\mathrm{m}$. However, also it was reported that stabilizing role of the STATCOM could be realized through regulating $\gamma[15,16,25]$.

Here in this work, the stabilizing function of STATCOM is obtained through modulation index loop, due to the merits of ease of implementation and observability of oscillation modes in the input signals. Therefore, the proportional $\mathrm{k}_{\mathrm{p} \gamma}$ and integral $\mathrm{k}_{\mathrm{i} \gamma}$ gains of the compensator of the DC-link voltage is not considered in the optimization process. Moreover, as the focus here is on the influential effect of the damping controller on the oscillations following the disturbances, thus the parameters of PI controller in the modulation index loop $\mathrm{k}_{\mathrm{pgm}}$ and $\mathrm{k}_{\mathrm{im}}$ are also not considered. The parameters of the stabilizing controller are only to be optimized.

Figure 4 shows that rotor speed deviation signal $\Delta \omega$ is taken as the main input for the stabilizing signal of the STATCOM. These returns to the following factors:-

- Ease of accessibility, as the rotor speed and hence speed deviation could be easily measured.

- Observability, as (2) and (18) indicate that oscillations in input/output powers are reflected to rotor speed and speed deviations.

Several forms of objective function were reported in the literature. They differ according to problem and design strategy. The objective function in this study is formulated to measure the ability and the speed of the proposed controller in damping the oscillations. Thus the 
objective function considers the input signal to the controller and the system output signals. It is integral time of the absolute error of the speed and power deviations as given by,

$$
f=\int_{0}^{t_{\text {sin }}} t\left(|\Delta \omega|+\left|\Delta p_{e}\right|\right) d t
$$

where $f$ is the objective function. $\mathbf{t}_{\text {sim }}$ is the time range of the simulation. Thus for calculating the objective function, the time-domain simulation of power system model has to be carried out over the simulation period $\left(0-\mathrm{ts}_{\mathrm{im}}\right)$. The problem of tuning STATCOM is converted to a constrained optimization problem, where the constraints are the lower and upper limits of the controller parameters,

Minimize $f$ subject to $\mathrm{G}_{\mathrm{mp}}{ }^{\text {lower }} \leq{ }_{\mathrm{mp}} \leq \mathrm{G}_{\mathrm{mp}}{ }^{\text {upper }}, \mathrm{mp}=1, \ldots \ldots, 5$

where $G_{m p}, G_{m p}$ lower and $G_{m p}$ upper are the parameters of the controller, lower and upper limits of each parameter independently. $\mathrm{mp}$ is the number of parameters to be optimized. The optimized parameters are

$$
\mathrm{G}_{\mathrm{mp}}=\left[\begin{array}{lllll}
\mathrm{k}_{\mathrm{c}} & \mathrm{T}_{1} & \mathrm{~T}_{2} & \mathrm{~T}_{3} & \mathrm{~T}_{4}
\end{array}\right]
$$

The optimized controller parameters are forecasted to vary in the following ranges,

$$
0<\mathrm{k}_{c} \leq 10 \text { and } 0<\mathrm{T}_{\mathrm{ii}} \leq 1
$$

where ii are either 1,2,3 or 4 . These limits are chosen to reduce the computation time, while achieving the required performance.

\section{Case Study}

The effectiveness and the reliability of the hybrid SA-PSO technique in optimal tuning of STATCOM controller parameters are validated by considering the three different load levels. These are shown in Table 1.

Table 1.

Loading levels for STATCOM controller design point

\begin{tabular}{|c|c|c|}
\hline Loading level & Load active power $\mathrm{P}(\mathrm{pu})$ & Load reactive power $\mathrm{Q}(\mathrm{pu})$ \\
\hline Light & 0.5 & 0.31 \\
\hline Nominal & 0.8 & 0.49 \\
\hline Heavy & 1.1 & 0.68 \\
\hline
\end{tabular}

The transient performance of SMIB without the STATCOM auxiliary damping control subjected to $20 \%$ step increase in the driving torque is shown in Figure 5. In producing Figure 5, the feedback signal from speed deviation $\Delta \omega$ is disabled, and the incremental modulation index $\Delta \mathrm{m}$ is solely power dependent as shown in Figure 4.

Figure 5 shows that the system becomes unstable for a small disturbance as $20 \%$ step increase in the driving torque when operating without the damping controller under nominal loading conditions. Thus, Figure 5 reveals the visibility of the STATCOM damping controller in restoring system stability, since without the stabilizing controller the system loses stability even for small disturbance.

The parameters of the STATCOM controller obtained from SA, PSO and SA-PSO are given in Table 2. 


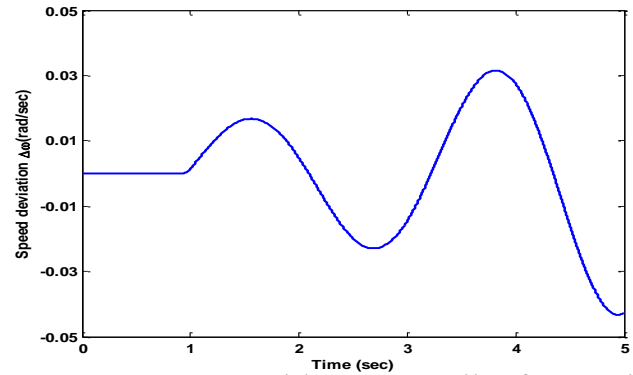

Fig. 5. Speed deviation $\Delta \omega$ without controller for nominal load level

Table 2.

Optimized parameters of STATCOM controller from SA, PSO and SAPSO for SMIB

\begin{tabular}{|c|c|c|c|}
\hline Parameters & SA & PSO & SA-PSO \\
\hline $\mathrm{K}_{\mathrm{c}}$ & 0.183 & 0.105 & 0.214 \\
\hline $\mathrm{T}_{1}$ & 0.8642 & 0.4856 & 0.6345 \\
\hline $\mathrm{T}_{2}$ & 0.2456 & 0.4327 & 0.375 \\
\hline $\mathrm{T}_{3}$ & 0.6245 & 0.3856 & 0.5012 \\
\hline $\mathrm{T}_{4}$ & 0.4215 & 0.6752 & 0.4892 \\
\hline
\end{tabular}

The computation times of the three optimization techniques were recorded for the investigated loading levels in Table 3.

Table 3.

Computation times in $\mathrm{m}$ sec for SA, PSO and SA-PSO

\begin{tabular}{|c|c|c|c|}
\hline $\begin{array}{c}\text { Loading } \\
\text { level }\end{array}$ & SA & PSO & SA-PSO \\
\hline light & 48.2 & 28.5 & 37.4 \\
\hline nominal & 45.8 & 27.2 & 36.4 \\
\hline heavy & 53.4 & 30.2 & 42.1 \\
\hline
\end{tabular}

Table 3 shows that PSO requires less computation time relatively compared with other techniques. However, this could be attributed to the search strategy of PSO in converging to local optimum. SA involves the longest time, which may be due to the disturbance mechanism in exploring the entire search universe to escape trapping into local minimal. The advised hybrid SA-PSO combines the advantages of both SA and PSO in exploring the search hyperspace in different paths; thus reducing the computation time while converging to the global optima.

The dynamic performance of SMIB under concern, Figure 1, subjected to $20 \%$ step increase in the input mechanical power are shown in Figures 6-8 for the three loading levels. The performance is illustrated in terms of speed, angular position and electrical power deviation for each load level. The parameters of the STATCOM control used for developing Figures 6-8 are obtained from Table 2 for SA, PSO and the advised hybrid SA-PSO.

\subsection{Light load}

The eigenvalues of the electromechanical modes of the SMIB equipped with STATCOM, Figure 1, corresponding for light loading scenario is given in Table 4. 
Table 4.

Light load eigenvalues of PSO, SA and SA-PSO

\begin{tabular}{|c|c|c|c|}
\hline & PSO & SA & SA-PSO \\
\hline Eigenvalues & - & - & - \\
(damping & $1.2353 \pm 6.952 \mathrm{i}$ & $1.611 \pm 7.852 \mathrm{i}$ & $2.2907 \pm 9.061 \mathrm{i}$ \\
ratio) & $(0.175)$ & $(0.201)$ & $(0.235)$ \\
\hline
\end{tabular}

The hybrid SA-PSO results in more stability margin than SA and PSO. Moreover, the SA-PSO provides the highest damping as shown in Table 4. The dynamic response of SMIB equipped with STATCOM controlled, while the controller is tuned using SA, PSO and SA-PSO for 20\% step increase in the input mechanical power is shown in Figure 6. The system performance is illustrated in terms of deviation in rotor speed, load angle and output electrical power.

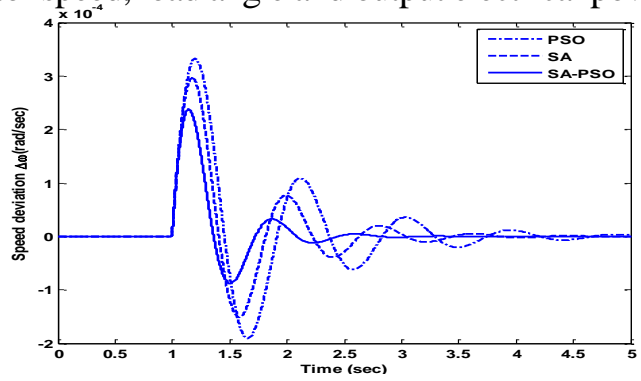

(a)

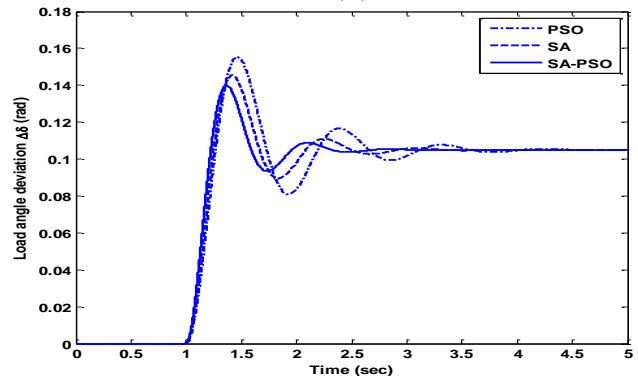

(b)

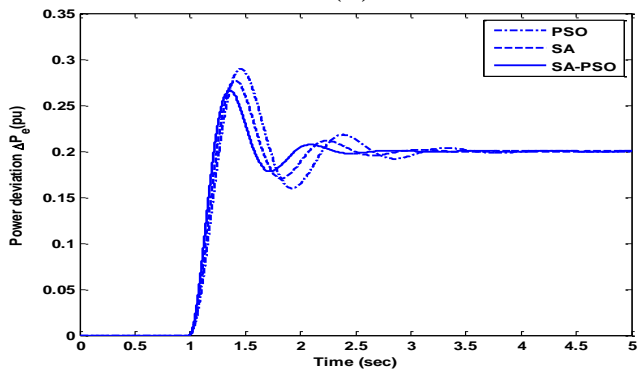

(c)

Fig. 6. Dynamic performance of SMIB system equipped with STATCOM case of light load for $20 \%$ step in mechanical input power in terms of (a) Speed $\Delta \omega(\mathrm{rad} / \mathrm{sec})$, (b) Rotor angle $\Delta \delta$ (rad), (c) Generated Power $\mathrm{P}_{\mathrm{e}}$ (pu), PSO (dot-dashed), SA (dashed), SA-PSO (solid)

The effectiveness and robustness of the advised SA-PSO compared with SA and PSO are illustrated in Figure 6. SA-PSO produces lowest overshoot and highest damping. The SA-PSO manages to restore the system stability following the disturbance in around 1.2sec, Figure 6, while SA and PSO require around $2 \mathrm{sec}$ and $2.5 \mathrm{sec}$ respectively for maintaining system stability. 
Ahmed A. A. Hafez, Synergy of simulated annealing and particle swarm algorithms for .........

\subsection{Nominal load}

Table 5 gives the eigenvalues corresponding to electromechanical modes for SMIB with STATCOM controlled by PSO, SA and SA-PSO for nominal load case.

Table 5.

Nominal load eigenvalues of PSO, SA and SA-PSO

\begin{tabular}{|c|c|c|c|}
\hline & PSO & SA & SA-PSO \\
\hline Eigenvalues & - & -1.402 & - \\
(damping ratio) & $1.1593 \pm 5.862 \mathrm{i}$ & $\pm 6.525 \mathrm{i}$ & $2.1363 \pm 7.875 \mathrm{i}$ \\
& $(0.194)$ & $(0.227)$ & $(0.284)$ \\
\hline
\end{tabular}

The proposed SA-PSO again produces highest damping ratio, Table 5. However, the stability margin for nominal loading condition is lower for the three controllers than light loading condition, which may be attributed to loading level that approaches the maximum operating limit. The performance of system under concern, Figure 1, is given in Figure 7 in terms of speed, angular position and electrical power deviation for each normal loading point.

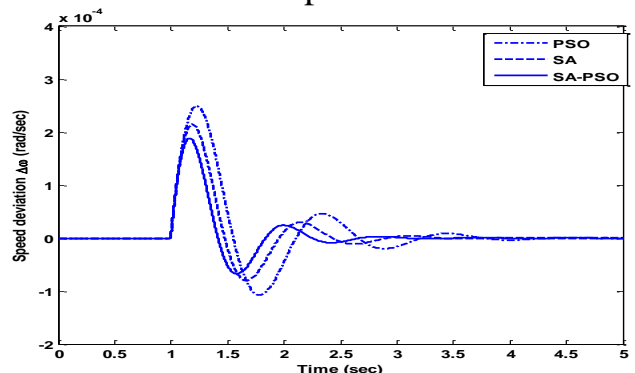

(a)

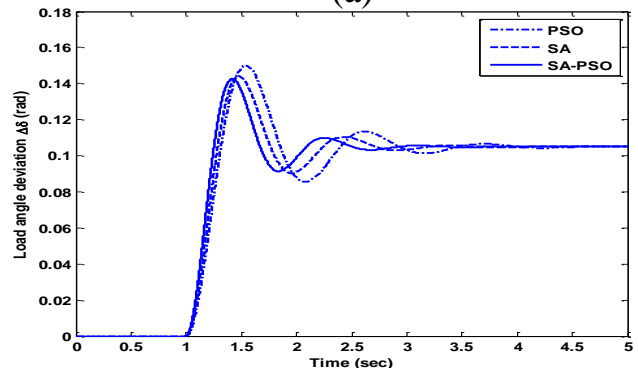

(b)

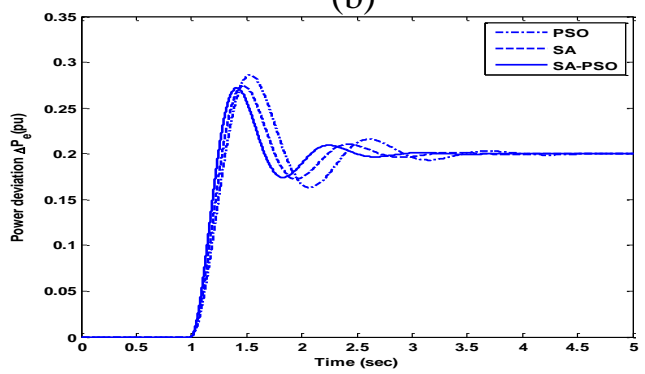

(c)

Fig. 7. Dynamic performance of SMIB system equipped with STATCOM case of nominal load for $20 \%$ step in mechanical input power in terms of (a) Speed $\Delta \omega(\mathrm{rad} / \mathrm{sec})$, (b) Rotor angle $\Delta \delta$ (rad), (c) Generated Power $\mathrm{P}_{\mathrm{e}}$ (pu), PSO (dot-dashed), SA(dashed), SA-PSO (solid) 
SA-PSO again produces the smallest settling time and overshoot compared with SA and PSO, Figure 7.The settling time of nominal load case is around $0.8 \mathrm{sec}$, which is around $35 \%$ less than light load. Even, the overshoot for this loading scenario is less compared with light load.

\subsection{Heavy load}

Eigenvalues of electromechanical modes of SMIB equipped with STATCOM in Figure 1 under heavy loading condition are given in Table 6.

Table 6.

Heavy load eigenvalue PSO, SA and SA-PSO

\begin{tabular}{|c|c|c|c|}
\hline & PSO & SA & SA-PSO \\
\hline Eigenvalues & - & -1.2682 & - \\
(damping & $0.8043 \pm 5.1263 \mathrm{i}$ & $\pm 5.925 \mathrm{i}$ & $1.758 \pm 7.034 \mathrm{i}$ \\
ratio) & $(0.155)$ & $(0.209)$ & $(0.2415)$ \\
\hline
\end{tabular}

Table 6 shows that the proposed SA-PSO improves the stability in terms of damping and margin compared with SA and PSO. Furthermore, SA-PSO gives nearly double damping ratio of PSO approach. Comparing Tables 4-6 reveals that as loading level increase, the stability margin decreases. The heavy loading levels are more close to limits of the system. Thus, large disturbance could result in losing the synchronism.

The dynamic response of SMIB equipped with SSSC controlled with a controller for $20 \%$ step increase in the input mechanical power is shown in Figure 8 for the case of heavy loading.

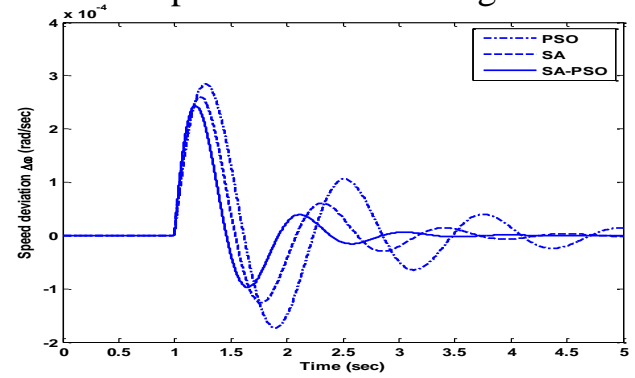

(a)

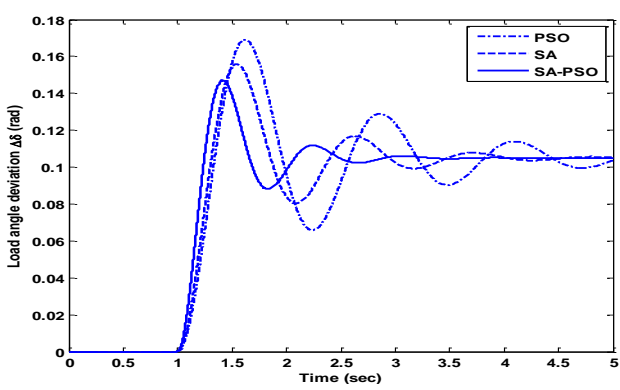

(b)

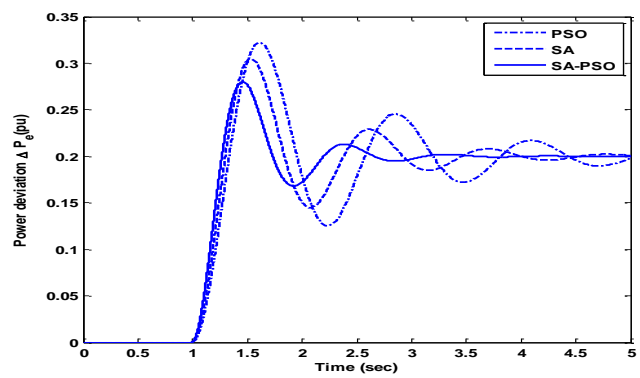

(c)

Fig. 8. Dynamic performance of SMIB system equipped with STATCOM case of heavy load for $20 \%$ step in mechanical input power in terms of (a) Speed $\Delta \omega(\mathrm{rad} / \mathrm{sec})$, (b) Rotor angle $\Delta \delta(\mathrm{rad})$, (c) Generated Power $\mathrm{P}_{\mathrm{e}}$ (pu), PSO (dot-dashed), SA(dashed), SA-PSO (solid)

Figure 8 continues to demonstrate the visibility of SA-PSO even under heavy loading conditions. SA-PSO successfully restores system operation under significant load step for 
Ahmed A. A. Hafez, Synergy of simulated annealing and particle swarm algorithms for .........

this hypothetical loading condition. The heavy loading case has prolonged settling time and highest overshoot compared to light and nominal loading conditions, Figures 6-8.

Figures 6-8 validate the effectiveness and robustness of the advised SA-PSO for optimal tuning of auxiliary STATCOM controller for SMIB system.

\section{Multi-machine power system}

The multi-machine power system considered here is three machines, 9 buses system, Figure 9. This is Western System Coordinated Council (WSCC) system. It was reported in the literature; the system parameters are given in [4, 39]. WSCC system has the merits of being compact and demonstrative.

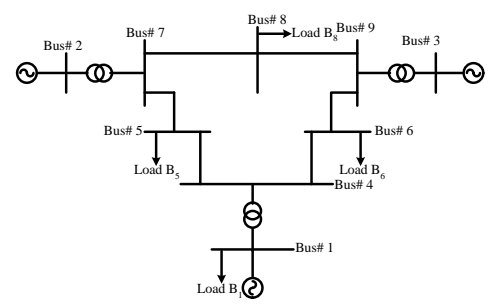

Fig. 9. Nine bus, multi-machine power system [4, 39]

The dynamic performance of n-machines MMP system could be described by a nonlinear model as given in equations (40)-(45), [4,36,39]. A number of assumptions given in references [36] are considered here in this work to ease the complexity of the system modelling. The first machine is taken as a reference. The electromechanical swing equations for i machine are,

$$
\begin{gathered}
\dot{\delta}_{i}=\omega_{s}\left(\omega_{i}-1\right) \\
\dot{\omega}_{i}=\frac{1}{M}\left(P_{m i}-P_{e i}-D_{i}\left(\omega_{i}-1\right)\right)
\end{gathered}
$$

Equations (40) and (41) are similar to equations (1) and (2) of SMIB system. Machine i electrical dynamics is given by,

$$
E_{q i}{ }^{\prime}=\frac{1}{T_{d o i}^{\prime}}\left(E_{f d i}-E_{q i}\right)
$$

Again equation (42) of i machine in n-machines MMP system is similar to equation (3) in SMIB. The machine i electrical equation is obtained from,

$$
E_{q i}=E_{q i}^{\prime}+\left(x_{d i}-\mathrm{X}_{d i}^{\prime}\right) I_{d i}
$$

where $I_{d i}$ is given by,

$$
I_{d i}=B_{i i} E_{q i}^{\prime}-\sum_{\substack{j=1 \\ j \neq i}}^{n} E_{q j}^{\prime} Y_{i j} \cos \left(\delta_{i}-\delta_{j}-\theta_{i j}\right)
$$

$\mathrm{P}_{\mathrm{ei}}$ is given by, 


$$
P_{e i}=G_{i i} E_{q i}^{\prime 2}+E_{q i}^{\prime} \sum_{\substack{j=1 \\ j \neq i}}^{n} E_{q j}^{\prime} Y_{i j} \sin \left(\delta_{i}-\delta_{j}-\theta_{i j}\right)
$$

where $i=1,2, \ldots \ldots \ldots, n . Y_{j i}$ is the amplitude of mutual admittance between bus $j$ and bus i. $Y_{\mathrm{ii}}$ is the amplitude of self- admittance of bus i. $\theta_{\mathrm{ji}}$ is the angle of $\mathrm{Y}_{\mathrm{ji}}$.

The small-signal model of MMP system is derived here using the Standard Linearization Technique (SLT) based on Taylor series approximation. The small-signal model of the MMP system could be obtained from reference [39].

\section{Objective function for STATCOM tuning in MMP system}

The parameters to be minimized, the inputs for the objective function of MMP system, are local and intra speed deviations and the deviation in the tie-lines power. Following a disturbance, if the controller successfully damps out the oscillations in these variables, the system would be presumably stable. Thus, speed and power deviations could be considered as good prognostic factors for measuring the stability of a MMP system. The objective function $f$ for the system under concern, Figure 9, is given by,

$$
f=\int_{0}^{t_{\text {ting }}} t\left(\left|\Delta \omega_{21}\right|+\left|\Delta \omega_{31}\right|+\left|\Delta \omega_{23}\right|+\left|\Delta p_{k}\right|\right) d t
$$

where $\mathrm{k}$ is the bus number at which STATCOM is attached. In this work, the STATCOM is attached to bus\# $2 . \Delta \mathrm{p}_{\mathrm{k}}$ is the change of the power of machine at bus \#2. The location and the input signal of damping controller of the STATCOM in the MMP under consideration are determined based on ref. [40]. Participation factor method, Concept of Sensitivity of PSS Effect (SPE) and Optimum PSS Location Index (OPLI) are used in [40] to identify the optimum location for PSS in WSCC system. However, the author in a future work will address the optimum location and input signals for advanced FACTS such as STATCOM, SSSC and UPFC in MMP systems using different methods as participation factor, Prony analysis and meta-heuristic optimization techniques.

Different scenarios of severe disturbances are considered for verifying the proposed controller in MMP system. However, only two distinct large disturbances are considered in the following while the system operating at nominal load; these are:

1. Case (1): A self-clearing 3-phase fault is applied in the transmission line 6-9 near bus\#6 at $\mathrm{t}=1 \mathrm{sec}$. The fault is cleared after 5-cycle and the original system is restored.

2. Case (2): A self-clearing 3-phase fault is applied in the transmission line 8-9 near bus\#8 at $\mathrm{t}=1 \mathrm{sec}$. The fault is cleared after 5-cycle and the original system is restored.

The parameters of STATCOM controller for MMP system are given in Table 7.

Table 7.

Optimized parameters of STATCOM controller from SA, PSO and SAPSO for MMP system

\begin{tabular}{|c|c|c|c|}
\hline Parameters & SA & PSO & SA-PSO \\
\hline $\mathrm{K}_{\mathrm{c}}$ & 0.0854 & 0.1845 & 0.1245 \\
\hline $\mathrm{T}_{1}$ & 0.745 & 0.524 & 0.6245 \\
\hline $\mathrm{T}_{2}$ & 0.2435 & 0.6824 & 0.5012 \\
\hline $\mathrm{T}_{3}$ & 0.5486 & 0.4583 & 0.4985 \\
\hline $\mathrm{T}_{4}$ & 0.4645 & 0.6123 & 0.5124 \\
\hline
\end{tabular}


Ahmed A. A. Hafez, Synergy of simulated annealing and particle swarm algorithms for .........

\section{Results and Discussions}

\subsection{Case (1)}

The dynamic behavior of MMP system under concern following a three-phase short circuit on line 6-9 near bus\#6 is illustrated in Figures 10-11 in terms of $\Delta \omega_{12}$ and $\Delta \omega_{23}$. The system operates at nominal loading level.

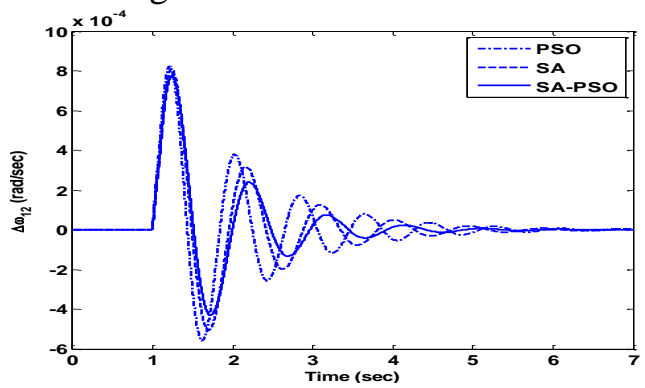

Fig. 10. $\Delta \omega_{12}$ for self-clearing three-phase fault on 6-9 transmission line under normal loading level, fault at $1 \mathrm{sec}$ and cleared at $1.083 \mathrm{sec}$

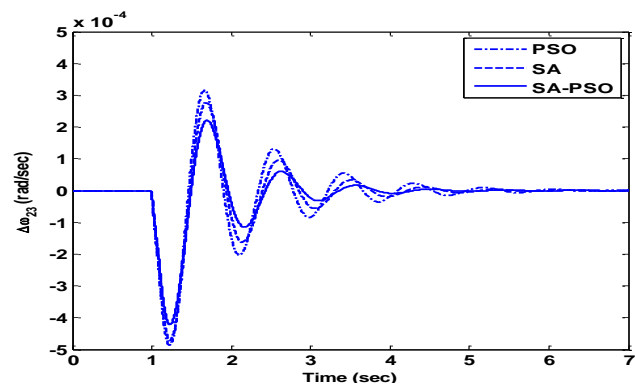

Fig. 11. $\Delta \omega_{23}$ for self-clearing three-phase fault on 6-9 transmission line under normal loading level, fault at $1 \mathrm{sec}$ and cleared at $1.083 \mathrm{sec}$

Figures 10-11 reveal the effectiveness of the advised SA-PSO scheme in restoring system stability under severe disturbance. The figures show that SA-PSO is superior to PSO and SA regarding settling time and overshoot percentage. The main settling times of PSO, SA and SA-PSO from Figures 12-13 respectively are 4.1, 3.21 and 2.5sec; this reveals the merits of SA-PSO controller. Speed deviation $\Delta \omega_{12}$, Figure 11, is more affected with fault on line 6-9 than $\Delta \omega_{23}$.This is attributed to location of the fault being between machines 1 and 3 .

Eigenvalues of electromechanical modes of MMP system for case (1) are given in Table 8.

Table 8.

Case (1) eigenvalues of MMP system for PSO, SA and SA-PSO

\begin{tabular}{|c|c|c|c|}
\hline Machine at Bus\# & PSO & SA & SA-PSO \\
\hline 1 & $-0.7853 \pm 7.665 \mathrm{i}$ & $-0.954 \pm 7.027 \mathrm{i}$ & $-1.21 \pm 6.39 \mathrm{i}$ \\
& $(0.102)$ & $(0.1345)$ & $(0.1861)$ \\
\hline 2 & $-0.9853 \pm 7.842 \mathrm{i}$ & $-1.159 \pm 7.457 \mathrm{i}$ & - \\
& $(0.1247)$ & $(0.153)$ & $1.401 \pm 6.859 \mathrm{i}$ \\
& & & $(0.201)$ \\
\hline 3 & $-0.7083 \pm 7.414 \mathrm{i}$ & $-0.855 \pm 6.786 \mathrm{i}$ & $-1.01 \pm 6.152 \mathrm{i}$ \\
& $(0.0951)$ & $(0.125)$ & $(0.162)$ \\
\hline
\end{tabular}


876

JES, Assiut University, Faculty of Engineering, Vol. 43, No. 6, November 2015, pp. 857 - 881

Table 8 shows that machine 2 experiences more stability margin than other machines. This is attributed to location of the disturbance between machines 1 and 3 .

\subsection{Case (2)}

Figures 12-13 show the dynamic behavior of MMP system under concern following a three-phase short circuit on line 8-9 near bus\#8in terms of $\Delta \omega_{12}$ and $\Delta \omega_{23}$. The system again operates at nominal loading level.

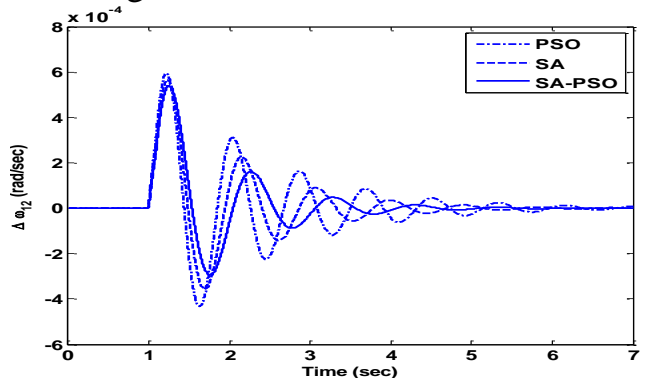

Fig. 12. $\Delta \omega_{12}$ for self-clearing three-phase fault on 8-9 transmission line under normal loading level, fault at $1 \mathrm{sec}$ and cleared at $1.083 \mathrm{sec}$

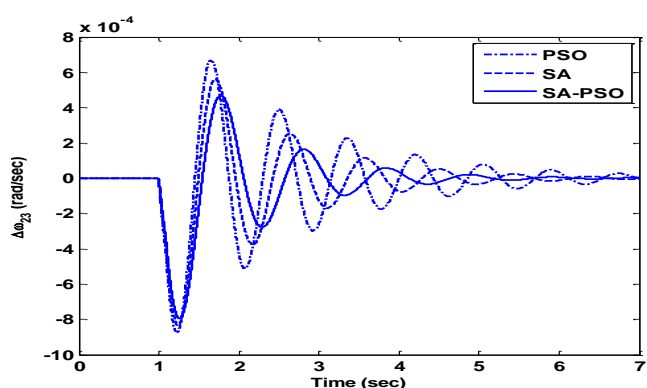

Fig. 13. $\Delta \omega_{23}$ for self-clearing three-phase fault on $8-9$ transmission line under normal loading level, fault at $1 \mathrm{sec}$ and cleared at $1.083 \mathrm{sec}$

The advised SA-PSO approach again maintains system stability under significant disturbance, as the three-phase short-circuit fault on the line 8-9 as shown in Figures 1213. The settling times of SA-PSO, SA and PSO respectively are nearly $3.5 \mathrm{sec}, 4.3 \mathrm{sec}$ and $6 \mathrm{sec}$. For this fault scenario, $\Delta \omega_{23}$ has higher overshoot than $\Delta \omega_{12}$, which owes to the location of the fault between machines 2 and 3 .

Figures 10-13 corroborate the visibility and applicability of the advised SA-PSO for optimal design of damping STATCOM controller for MMP system.

Table 9 shows the eigenvalues of electromechanical modes of MMP system for case (2).

\section{Table 9.}

Case (2) eigenvalues of MMP system for PSO, SA and SA-PSO

\begin{tabular}{|c|c|c|c|}
\hline Machine at Bus\# & PSO & SA & SA-PSO \\
\hline 1 & - & $-1.154 \pm 6.974 \mathrm{i}$ & $-1.42 \pm 6.848 \mathrm{i}$ \\
& $0.9865 \pm 7.225 \mathrm{i}$ & $(0.1633)$ & $(0.203)$ \\
& $(0.1353)$ & & \\
\hline 2 & $-0.845 \pm 7.79 \mathrm{i}$ & $-0.987 \pm 6.848 \mathrm{i}$ & $-1.21 \pm 6.602 \mathrm{i}$ \\
& $(0.1225)$ & $(0.1427)$ & $(0.1803)$ \\
\hline 3 & $-0.818 \pm 7.523 \mathrm{i}$ & $-0.896 \pm 6.654 \mathrm{i}$ & $-1.111 \pm 6.234 \mathrm{i}$ \\
& $(0.106)$ & $(0.1335)$ & $(0.1755)$ \\
\hline
\end{tabular}


Ahmed A. A. Hafez, Synergy of simulated annealing and particle swarm algorithms for .........

In case (2), the fault scenario is on line 8-9; thus machine 1 is less effected as shown in Table 9 in terms of stability margin. Table 8 and 9 reveal that machine 3 experiences less stability margin and damping ratio for the considered cases in MMP system.

\section{Conclusions}

Hybrid SA-PSO is considered for optimal tuning of STATCOM auxiliary controller, to damp the electromechnical oscillations following different disturbance levels in SMIB and MMP systems. Comprehensive analysis and detailed simulation are carried out to verify the proposed controller against SA and PSO schemes. The following conclusions could be extracted:

1. Meta-heuristic optimization approaches are considered for optimal tuning of STATCOM, which increases stability margin and reducing settling time under various loading levels.

2. The advised SA-PSO converges to optimal solution across the entire domain.

3. SA-PSO generates high-quality solutions with less computation requirements and offers more stable margins.

4. SA-PSO successfully acquires the merits of the SA in converging to global optimal and PSO in simplicity, while avoiding their limitations as local minimum entrapping of PSO and sophisticated search requirements of SA.

5. Figures 6-8 and Figures 10-13 validate the visibility and effectiveness of the advised SA-PSO for optimal tuning of STATCOM damping controller either in SMIB or in MMP systems.

\section{REFERENCES}

[1] R. Dubey; S. Dixit and G. Agnihotri, "Optimal Placement of Shunt Facts Devices Using Heuristic Optimization Techniques: An Overview," Fourth International Conference on Communication Systems and Network Technologies (CSNT-2014), pp. 518-523, 2014.

[2] M. H. Haque, "Use of series and shunt FACTS devices to improve first swing stability limit," The 7th International Power Engineering Conference, IPEC 2005, pp. 1-365, 2005.

[3] A. Kumar and G. Priya, "Power system stability enhancement using FACTS controllers," International Conference on Emerging Trends in Electrical Engineering and Energy Management (ICETEEEM 2012), pp. 84-87, 2012.

[4] P. Kundur, Power System Stability and Control, McGraw-Hill, 1994.

[5] B. Lahshmananayak and G. Venkataratnam, "Reactive power control in long transmission line," International Conference on Sustainable Energy and Intelligent Systems (SEISCON 2011), pp. 427-431, 2011.

[6] R. Elmoudi; I. Grinberg and M. Safiuddin, "Design and implementation of Static VAR Compensator for classroom and research applications in Smart Grid laboratory," IEEE International Conference on Smart Grid Engineering (SGE 2012), pp. 1-8, 2012.

[7] Y. Qingguang; L. Pei; L. Wenhu and X. Xiaorong, "Overview of STATCOM technologies," Proceedings of the 2004 IEEE International Conference on Electric Utility Deregulation, Restructuring and Power Technologies (DRPT 2004).Vol. 2, pp. 647-652, 2004.

[8] G. Shahgholian; J. Faiz; B. Fani and M. R. Yousefi, "Operation, modeling, control and applications of static synchronous compensator: A review," Conference Proceedings IPEC 2010, pp. 596-601, 2010.

[9] B. Singh; R. Saha; A. Chandra and K. Al-Haddad, "Static synchronous compensators (STATCOM): a review," IET Power Electronics, Vol. 2, pp. 297-324, 2009.

[10] T. Larsson and C. Poumarede, "STATCOM, an efficient means for flicker mitigation," IEEE Power Engineering Society 1999 Winter Meeting, Vol. 2, pp. 1208-1213, 1999.

[11] G. Radman and J. Shultz, "A new method to account for STATCOM losses in power flow analysis," Proceedings of the 35th Southeastern Symposium on System Theory, pp. 477-481, 2003. 
[12] S. Singiresu, R., Engineering Optimization Theory and Practice, New Jersey: John Wiley \& Sons, 2009.

[13] M. Zarringhalami; S. M. Hakimi, and M. Javadi, "Optimal regulation of STATCOM controllers and PSS parameters Using Hybrid Particle Swarm Optimization," 14th International Conference on Harmonics and Quality of Power (ICHQP 2010), pp. 1-7, 2010.

[14] K. Kumarasamy and R. Raghavan, "Particle Swarm Optimization algorithm for voltage stability improvement using multiple STATCOM," International Conference on Emerging Trends in Electrical Engineering and Energy Management (ICETEEEM 2012), pp. 235-242, 2012.

[15] L. Chien-Hung and Y.-Y. Hsu, "Design of a Self-Tuning PI Controller for a STATCOM Using Particle Swarm Optimization," IEEE Transactions on Industrial Electronics, Vol. 57, pp. 702-715, 2010.

[16] M. A. Abdul-Malek and M. A. Abido, "STATCOM based controller design using Particle Swarm Optimization for power system stability enhancement," IEEE International Symposium on Industrial Electronics, ISIE 2009, pp. 1218-1223, 2009.

[17] S. F. Faisal and A. H. M. A. Rahim, "A robust STATCOM damping controller for a multi-machine power system," The 7th International Power Engineering Conference, IPEC 2005, pp. 1-371, 2005.

[18] W. Hui, M. Xiang-ping, Z. Liang, and Z. Tie-min, "Controlling study of DSTATCOM based on Hybrid Genetic Optimization PID algorithm," 24th Chinese Control and Decision Conference (CCDC 2012), pp. 2762-2766, 2012.

[19] M. A. Abido, "Design of PSS and STATCOM-based damping stabilizers using genetic algorithms," IEEE Power Engineering Society General Meeting, pp. 0 -8, 2006.

[20] Y. del Valle; M. Digman, A. Gray; J. Perkel, G. K. Venayagamoorthy and R. G. Harley, "Enhanced particle swarm optimizer for power system applications," IEEE Swarm Intelligence Symposium, SIS 2008, pp. 1-7, 2008.

[21] F. S. Al-Ismail; M. A. Hassan and M. A. Abido, "RTDS Implementation of STATCOM-Based Power System Stabilizers," Canadian Journal of Electrical and Computer Engineering, Vol. 37, pp. 48-56, 2014.

[22] Q. Liu and Z. Wang, "Coordinated design of multiple FACTS controllers based on fuzzy immune coevolutionary Algorithm," IEEE Power \& Energy Society General Meeting, PES '09, pp. 1-6, 2009.

[23] F. S. Al-Ismail and M. A. Abido, "The impact of STATCOM based stabilizers on Power System Stability, using intelligent computational optimization approach," IEEE PES Innovative Smart Grid Technologies Asia (ISGT 2011), pp. 1-13, 2011.

[24] D. Z. Fang; S. Q. Yuan; Y. J. Wang and T. S. Chung, "Coordinated parameter design of STATCOM stabiliser and PSS using MSSA algorithm," IET Generation, Transmission \& Distribution, Vol. 1, pp. 670-678, 2007.

[25] C. Hongjun; L. Jing and Z. Xin, "PSO-based self-tuning PI control for STATCOM," 7th International Power Electronics and Motion Control Conference (IPEMC 2012), pp. 2710-2715, 2012.

[26] Z. Fengrui; C. Jianshu and X. Zhenhui, "An improved Particle Swarm Optimization Particle Filtering algorithm," International Conference on Communications, Circuits and Systems (ICCCAS 2013), pp. 173-177, 2013.

[27] L. Lin, L. Qi, L. Jun-yong, and L. Chuan, "An improved particle swarm optimization algorithm," IEEE International Conference on Granular Computing, GrC 2008, pp. 486-490, 2008.

[28] G. G. Samuel and C. C. Asir Rajan, "Hybrid Particle Swarm Optimization; Genetic algorithm and Particle Swarm Optimization \&\#x2014; Evolutionary programming for long-term generation maintenance scheduling," International Conference on Renewable Energy and Sustainable Energy (ICRESE 2013), pp. 227-232, 2013.

[29] C. Fan and Y. Wan, "An adaptive simple particle swarm optimization algorithm," Chinese Control and Decision Conference, CCDC 2008, pp. 3067-3072, 2008.

[30] H. Shan; S. Li; D. Gong and P. Lou, "Genetic simulated annealing algorithm-based assembly sequence planning," International Technology and Innovation Conference, ITIC 2006, pp. 1573-1579, 2006.

[31] Rodri, x D. guez; F. J. C. Garcia-Martinez and M. Lozano, "A GA-based multiple simulated annealing," IEEE Congress on Evolutionary Computation (CEC 2010), pp. 1-7, 2010. 
Ahmed A. A. Hafez, Synergy of simulated annealing and particle swarm algorithms for .........

[32] M. M. Keikha, "Improved Simulated Annealing Using Momentum Terms," Second International Conference on Intelligent Systems, Modelling and Simulation (ISMS 2011), pp. 44-48, 2011.

[33] L. Soo-Young and L. Kyung Geun, "Synchronous and asynchronous parallel simulated annealing with multiple Markov chains," IEEE Transactions on Parallel and Distributed Systems, Vol. 7, pp. 993-1008, 1996.

[34] W. Wenbo; L. Lin and Y. Xinyu, "Improved simulated annealing algorithm for task allocation in real-time distributed systems," IEEE International Conference on Signal Processing, Communications and Computing (ICSPCC 2014), pp. 50-54, 2014.

[35] J. Rose; W. Klebsch and J. Wolf, "Temperature measurement and equilibrium dynamics of simulated annealing placements," IEEE Transactions on Computer-Aided Design of Integrated Circuits and Systems, Vol. 9, pp. 253-259, 1990.

[36] J. J. Grainger and W. D. Stevenson, Power System Analysis, McGraw-Hill, 1994.

[37] IEEE Recommended Practice for Excitation System Models for Power System Stability Studies," IEEE Std 421.5-2005, pp.0_1-85, 2006.

[38] C. Richard, Dorf and H. Robert, Bishop, Modern Control Systems, 12 ed.: Prentice Hall, 2010.

[39] R.Yadaiah and N. Venkata Ramana" Lineraisation of multi-machine power system : Modeling and control-A survey" Electrical Power and Energy Systems, Vol. 29, pp. 297-311, 2007.

[40] D. Mondal, A. Chakrabarti and A. Senguota " Selection of optimum location of power system stabilizer in a multimachine power system" Journal of Electrical and Electronics Engineering Research, Vol. 2, pp. 001-013, 2010. 


\section{Appendix}

The parameters of the SMIB and STATCOM are given in Table A1. Loading of WSCC is given in Table A2.

Table A1.

Parameters of SMIB system equipped with STATCOM

\begin{tabular}{|c|c|}
\hline Generator & $\begin{array}{c}\mathrm{M}=8 \mathrm{MJ} / \mathrm{MVA}, \mathrm{X}_{\mathrm{d}}=1 \mathrm{pu}, \mathrm{X}_{\mathrm{q}}=0.7 \mathrm{pu}, \mathrm{X}_{\mathrm{d}}^{\prime}=0.3 \mathrm{pu}, \mathrm{D}=0, \mathrm{~V}_{\mathrm{s}}=1.0, \\
\mathrm{~T}_{\mathrm{do}}^{\prime}=5.044 \mathrm{sec}\end{array}$ \\
\hline Excitation system & $\mathrm{K}_{\mathrm{A}}=10, \mathrm{~T}_{\mathrm{A}}=0.05 \mathrm{sec}$ \\
\hline Power transformer & $\mathrm{X}_{\mathrm{T}}=0.1 \mathrm{pu}$ \\
\hline Transmission lines & $\mathrm{X}_{\mathrm{L} 1}=\mathrm{X}_{\mathrm{L} 2}=\mathrm{X}_{\mathrm{L} 3}=\mathrm{X}_{\mathrm{L} 4}=0.05 \mathrm{pu}$ \\
\hline STATCOM & $\mathrm{V}_{\mathrm{dc}}=1.0, \mathrm{C}_{\mathrm{dc}}=1.0, \mathrm{X}_{\mathrm{c}}=0.015$ \\
\hline $\begin{array}{l}\text { Parameters of the } \\
\text { controller }\end{array}$ & $\begin{array}{c}\mathrm{T}_{\mathrm{w}}=0.8, \mathrm{k}_{\mathrm{p \gamma}}=1.42, \mathrm{k}_{\mathrm{i \gamma}}=0.75, \mathrm{k}_{\mathrm{pgm}}=2.54 \\
\mathrm{k}_{\mathrm{im}}=0.683\end{array}$ \\
\hline
\end{tabular}

Table A2.

Nominal loading of MPP WSCC system [4, 39]

\begin{tabular}{|c|c|c|c|c|}
\hline \multirow{2}{*}{ Bus\# } & \multicolumn{2}{|c|}{ Generated power } & \multicolumn{2}{c|}{ load power } \\
\cline { 2 - 5 } & $\mathrm{P}(\mathrm{pu})$ & $\mathrm{Q}(\mathrm{pu})$ & $\mathrm{P}(\mathrm{pu})$ & $\mathrm{Q}(\mathrm{pu})$ \\
\hline 1 & 1.72 & 0.64 & 1.0 & 0.4 \\
\hline 2 & 1.65 & 0.0865 & - & - \\
\hline 3 & 0.98 & -0.45 & - & - \\
\hline 4 & - & - & - & - \\
\hline 5 & - & - & 1.3 & 0.5 \\
\hline 6 & - & & 1.0 & 0.4 \\
\hline 7 & - & & - & - \\
\hline 8 & - & & 1.0 & 0.35 \\
\hline 9 & - & - & - & - \\
\hline
\end{tabular}

100MVA is taken as base for the 9-bus WSCC system [4, 39]. 
Ahmed A. A. Hafez, Synergy of simulated annealing and particle swarm algorithms for .........

\section{التآزر بين خوارزميات محاكاة التقية لتشكيل المعادن وسرب الجسميات لتصميم فعال

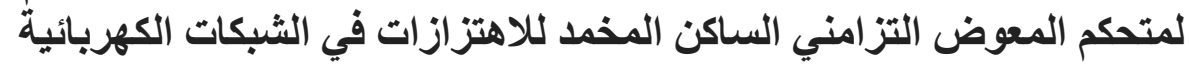

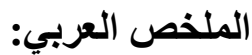

هذا البحث يقترح طريقة مبنكرة للتآزر بين خو ارزميات محاكاة التقسية لتنكيل المعادن وسرب الجسيمات

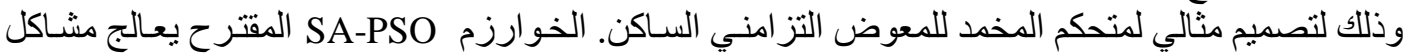

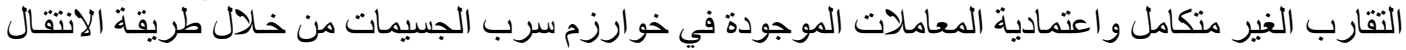

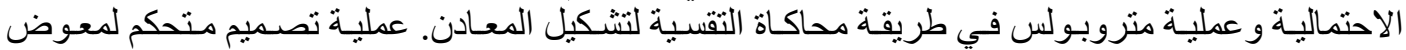

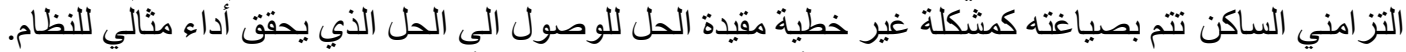

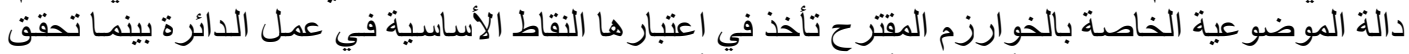

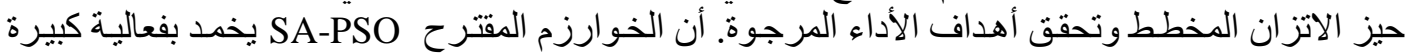

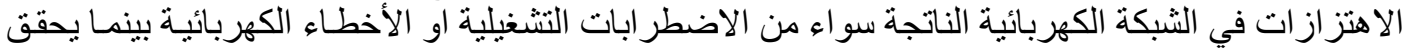

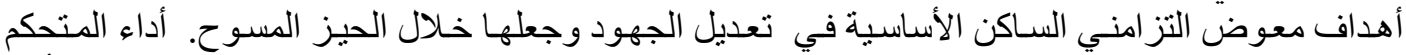

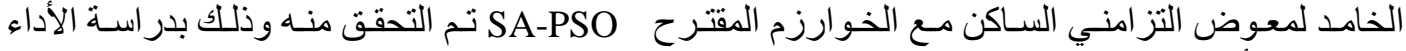

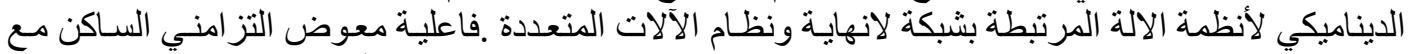

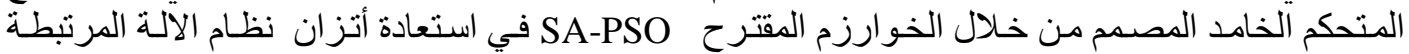

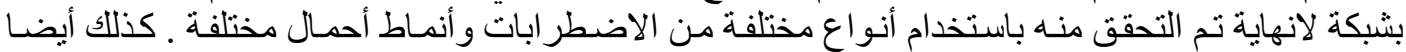

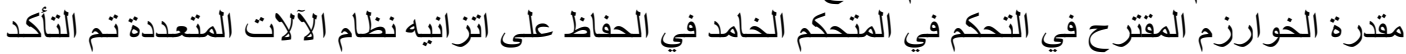

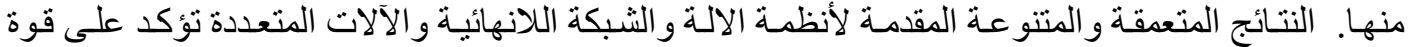

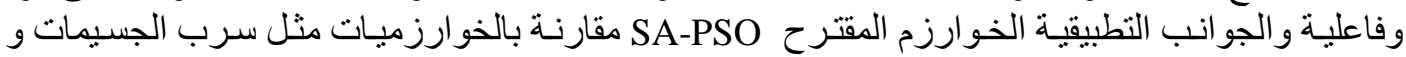
محاكاة التقسية لتشكيل المعادن. 